

O ESPACYO GEOGRÁFICO EM ANÁLISE

\title{
TERRITÓRIO E SAÚDE NA GEOGRAFIA DE MILTON SANTOS: TEORIA E MÉTODO PARA O PLANEJAMENTO TERRITORIAL DO SISTEMA ÚNICO DE SAÚDE NO BRASIL
}

\section{TERRITORY AND HEALTH IN MILTON SANTOS GEOGRAPHY: THEORY AND METHOD FOR TERRITORIAL PLANNING THE UNIQUE HEALTH SYSTEM IN BRAZIL}

Rivaldo Mauro Faria Universidade Federal de Santa Maria - UFSM

Santa Maria, RS, Brasil e-mail: rivaldogeo@hotmail.com

Arleude Bortolozzi Universidade Estadual de Campinas - Unicamp

Campinas, $S P$, Brasil e-mail:ar.leude@hotmail.com.

\section{Recebido em: 12/11/2015}

\section{Resumo}

AA geografia de Milton Santos vem sendo amplamente incorporada no planejamento territorial do Sistema Único de Saúde (SUS) no Brasil. Sua proposta baseada no conceito de "território usado" é ainda hoje referência para a definição da porta de entrada das redes de atenção à saúde do SUS. Contudo, os instrumentos normativos de planejamento territorial ainda carecem de embasamento teórico e de método mais aprofundado. Há a apropriação do conceito e a generalização do seu uso, mas falta reflexão e crítica. Por isso, já passados mais de vinte anos da apresentação da sua proposta do "retorno do território", consideramos relevante refazer o caminho teórico do conceito de "território usado", à luz e nos termos propostos originalmente por Milton Santos. Esse é o primeiro objetivo desse artigo. O segundo objetivo, não menos importante, é entender como esse conceito vem sendo utilizado em propostas efetivas de planejamento territorial do SUS. A metodologia é baseada num trabalho teórico-descritivo, de um lado, com função de iluminar teoricamente o conceito; e num exercício teórico-crítico, de outro, com função de método. Os resultados teóricos encontrados indicaram equívocos na apropriação do conceito de "território usado" pela saúde no Brasil e a necessidade de aprofundar sua discussão, sobretudo na dimensão da totalidade que lhe é inerente.

Palavras-chave: Território Usado; Planejamento Territorial; Territorialização; Sistema Único de Saúde. 


\begin{abstract}
The geography of Milton Santos has been incorporated into the territorial planning of the Unique Health System (SUS) in Brazil. The conceptual proposal based on the concept of "used territory" is still a reference for the definition of SUS gateway and the modeling of their care networks. However, the legal instruments of territorial planning still require theoretical foundation and methodology further. There is the generalization of its use, but lacks reflection and criticism. Therefore, the first objective of this paper is to remake the theoretical path of "used territory" concept and as proposed originally by Milton Santos. Therefore, the first objective of this paper is to remake the path theoretical of "territory used" concept as originally proposed by Milton Santos. The second goal is to understand how this concept has been used in effective proposals of territorial planning of SUS. The methodology is based on a theoretical and descriptive work and a theoretical-critical exercise. The results indicated mistakes in appropriation of concept of "used territory" by health in Brazil and the need to deepen the discussion, especially in dimension of totality that is inherent.
\end{abstract}

Key-words: Used Territory; Territorial Planning; Territorialization; Unique Health System.

\title{
1. INTRODUÇÃO
}

É amplamente conhecida a influência de Milton Santos nas abordagens territoriais dos problemas de saúde no Brasil (CZERESNIA e RIBEIRO, 2000; FARIA e BORTOLOZZI, 2009). Maior ainda é sua influência nas ações de planejamento territorial dos serviços de saúde do Sistema Único de Saúde (SUS), sobretudo na implantação das redes de atenção e na definição dos limites territoriais de atuação das unidades de atenção primária à saúde.

Desde a década de 1980 diversos estudos, seja na geografia da saúde, na medicina social, na epidemiologia ou ainda na psicologia social, vêm sendo realizados sob a influência teórica de Milton Santos. Essa influência se fez notar, inicialmente, na necessidade de discutir o contexto geográfico dos problemas de saúde. Foi ainda aprofundada pela carência, naquele momento, de instrumentos teórico-metodológicos que permitissem superar a visão ecológica da determinação linear (uni-multicausal, tipo causa-efeito), tão 
comum nas obras clássicas de geografia médica, com destaque, no Brasil, para os estudos parasitológicos feitos por Lacaz (1972) e Pessoa (1978). Os trabalhos desenvolvidos por Barreto (1982), na Bahia, e Silva (1985), em São Paulo, expressam bem essa influência. Posteriormente, a teoria miltoniana vai adentrando as questões do planejamento territorial, em especial, ainda na década de 1980, com as propostas de implantação do Sistema Locais de Saúde (SILOS) através dos chamados Distritos Sanitários. É quando são apresentadas as primeiras propostas de territorialização da saúde no Brasil (UNGLERT, 1993).

A implantação do SUS na década de 1990, associado às mudanças demográficas e epidemiológicas da população brasileira, irá anunciar um novo ciclo dessa influência. De um lado, a complexidade dos problemas saúde, representada por uma dupla carga epidemiológica (assim definida pela manutenção ou mesmo aumento das doenças infecciosas e o crescimento das doenças crônico-degenerativas) e, de outro, a política de universalização e descentralização dos serviços, sob a égide da municipalização da atenção básica através do "Programa Agentes Comunitário de Saúde" (criado em 1991) e do Programa Saúde da Família (criado em 1994). Esse contexto social de saúde profundamente complexo (que vai exigir novas ações de vigilância e novos modelos assistenciais), vai impor a necessidade de novas abordagens teórico-metodológicas do espaço e do território na saúde. Então, a geografia de Milton Santos, talvez pela sua capacidade de atravessar as fronteiras da própria disciplina, será amplamente utilizada pelas ciências médicas e sociais preocupadas com a problemática da saúde (mesmo a geografia da saúde parece se renovar à luz desses novos desafios, inserindo questões secundárias na tradicional geografia médica, como as doenças crônicodegenerativas, a rede assistencial, a mobilidade e o acesso aos serviços de saúde, entre outras).

O início de século irá ainda aprofundar esses desafios e enriquecer essa aproximação entre a geografia miltoniana e as ciências da saúde. Com a diferença que nesse momento parece ser o território e não mais o espaço 
geográfico o conceito em voga. Observa-se um movimento parecido ao que vivenciou o próprio autor, que vai da conceituação do espaço à conceituação do território. É sabido que Milton Santos dedicou a maior parte da sua vida acadêmica ao estudo da "natureza do espaço". Razão do nome da sua obra reconhecidamente mais importante (SANTOS, 1996), pois expressa, conforme o próprio autor, a trajetória de reflexão que se iniciou na década de 1970 em "Por uma geografia nova" (SANTOS, 1978), tendo como interregno, entre outros, os textos de "Espaço e Método" (SANTOS, 1985) e Metamorfoses do Espaço Habitado (1988). Portanto, é o espaço o conceito central da obra de Milton Santos. O território é um conceito secundário, embora nunca estivesse ausente, assim como os conceitos de região, paisagem, rede e lugar.

Entretanto, desde que propôs o "retorno do território", ainda em 1992, no "Encontro Internacional: o novo mapa do mundo", cuja conferência foi repetidamente publicada (SANTOS, 1994), o próprio autor vai privilegiando uma discussão territorial, na acepção do uso do território ou território usado (ambas as expressões são encontradas). Esse movimento teórico pode ser observado tanto na sua obra "A natureza do espaço" (SANTOS, 1996), onde o território aparece numa discussão bem mais aprofundada que àquela da configuração territorial presente em "Metamorfoses do espaço habitado" (1988), quanto nos livros "Por uma outra globalização" (SANTOS, 2006) e "Brasil: território e sociedade no século XXI" (SANTOS e SILVEIRA, 2001). Expressão mais significativa desse movimento teórico é a apresentação da conferência intitulada "O papel ativo da Geografia: um manifesto" no XII Encontro Nacional de Geógrafos (SANTOS, 2000). Possivelmente este seja o texto que melhor discute o conceito de "território usado", embora na literatura da saúde esteja praticamente ausente. Um autor que muito bem destacou esse movimento teórico de Milton Santos e a importância do "Manifesto" foi Moraes (2013), numa das poucas obras a perscrutar os sentidos do conceito de território na geografia da Milton Santos.

Portanto, é na perspectiva dos usos do território que teoria miltoniana vai adentrar ainda mais o debate das questões de saúde no Brasil. Expressão 
significativa é a presença do próprio Milton Santos no "I Seminário Nacional Saúde e Ambiente no Processo de Desenvolvimento", realizado em julho de 2000, possivelmente uma das suas últimas conferências. Ocasião que o próprio utiliza para enfatizar que a "[...] categoria analítica é o território usado pelos homens, tal qual ele é, isto é, o espaço vivido pelos homens [...]" (SANTOS, 2003, p 3010).

Contudo, se há, de acordo com Moraes (2013), certa imprecisão no conceito de território usado (talvez pela pouca explicitação epistemológica pelo próprio Milton. Santos), maiores incertezas e equívocos serão observados na sua aplicação. A começar pelo superdimensionamento, como se tudo pudesse ser compreendido a partir do uso do território. E sabemos que isso não é verdade. Algumas abordagens da saúde e do planejamento dos serviços talvez fossem mais adequadas utilizando-se os conceitos de lugar, região, rede e paisagem.

A generalização/massificação do uso do conceito de território usado impõe um desafio de reflexão, pois é tênue o caminho que conduz a descaracterização do próprio conceito. São leituras e releituras feitas em contextos geográficos e históricos diferentes ou ainda experiências de pesquisa e propostas de planejamento territorial aplicadas e reaplicadas descuidadamente, incentivadas pelos "chavões" disseminados irrestritamente ("o território usado é o chão mais a identidade"; "o território usado é o espaço banal"; "o território usado é sinônimo de espaço geográfico", entre outros). Isso traz o risco da aplicação inadequada do conceito e as consequências vão se refletir diretamente nas ações do planejamento territorial dos serviços de saúde do SUS.

Esse desafio de reflexão e as questões a ele inerentes motivaram-nos a refazer o caminho teórico do território usado, à luz e nos termos propostos originalmente por Milton Santos. Este é o primeiro objetivo deste trabalho, ou seja, iluminar teoricamente o conceito. Tal como expresso, o definimos como um trabalho teórico-descritivo, realizado em algumas obras estrategicamente selecionadas. 
Contudo, apresenta-se a pergunta de saber se o uso desse conceito pelos profissionais e pesquisadores da saúde é condizente com a teoria originalmente proposta. Este é o segundo objetivo e ele tem uma natureza de método, ou seja, pretende-se entender os usos do conceito em situaçõesproblema. Efetivamente, propõe-se entender a inserção do conceito de território usado no planejamento territorial dos serviços de saúde do SUS. E para atender esse objetivo, da mesma forma, selecionamos algumas propostas acadêmicas e instrumentos normativos do planejamento territorial produzidos sob a influência miltoniana.

O texto foi organizado em três seções e tendo em vista esses dois objetivos. A primeira parte discute o conceito de território na geografia de Milton Santos. É um trabalho histórico-bibliográfico, sem perscrutar epistemologicamente uma obra em específico, mas com intuito de compreender a evolução do entendimento do território pelo autor. A segunda parte refaz a discussão conceitual do território usado a partir do texto do "Retorno do Território" (SANTOS, 1993) até a proposição do "Manifesto" (SANTOS, 2000). Finalmente, a terceira parte, apresenta a influência desse conceito no planejamento territorial dos serviços de saúde do SUS e o equívoco da sua associação com as propostas territorialização da saúde no Brasil.

\section{O CONCEITO DE TERRITÓRIO NA TEORIA DE MILTON}

Revisitar a teoria do autor é importante para iluminar questões que o tempo se encarregou de secundarizar ou ainda questões que originalmente eram irrelevantes, mas que o tempo se encarregou de destacar. Obviamente não é o tempo em si, mas a distância entre a teoria e as leituras e releituras que vão sendo feitas. A ponto de o conceito ganhar dimensões e aplicações relativamente alheias à sua proposta inicial. Obviamente, isso não é regra, é bom que se diga. Mas quando a teoria extrapola as fronteiras da própria 
disciplina, como é o caso, as descaracterizações podem ser mais frequentes ou ainda mais aprofundas.

"É o uso do território, não o território em si mesmo, que faz dele objeto de análise social” (SANTOS, 1994, p. 15). Nestes termos, Milton Santos resume sua abordagem territorial e a integra à sua teorização mais ampla da natureza do espaço humano. Talvez isso explique a ausência de uma teorização do território pelo autor, dado que já o havia feito na sua obra "A natureza do espaço". De fato, Milton Santos não se dedicou ao estudo teóricoepistemológico do conceito de território. Não porque não era necessário, mas porque o integra a um caminho teórico coerente e pouco ortodoxo que vinha desenvolvendo desde a década de 1970. Antes disso, a influência dos postulados clássicos da geografia francesa o fez produzir uma geografia regional bastante politizada, porém, relativamente alheia ao conceito de território (na sua acepção mais ampla, não apenas político-administrativa), nos moldes de uma "Geografia Ativa” de Pierre George (1966).

A proposta conceitual baseada no uso do território ou território usado, só vai aparecer na década de 1990. Isso em um momento em que as perspectivas baseadas na teoria dos sistemas e na fenomenologia estão arraigadas em sua obra (MORAES, 2014) ${ }^{1}$.É reconhecida a influência marxista de inspiração estruturalista na geografia de Milton Santos. Razão pela qual o território vai aparecer quase sempre associado ao limite político do Estado. Isso é bastante evidenciado em suas obras publicadas entre 1970 e 1990 (SANTOS, 1978; 1979a; 1979b; 1985; 1987; 1988, entre outras). Por isso, a acepção "espaço nacional" será frequentemente utilizada para referir-se ao território político do Estado, ao passo que o espaço geográfico será uma porção delimitada deste. Portanto, o espaço geográfico é, nesse contexto, o recorte social e histórico do território político do Estado. Não há equivalência entre esses dois conceitos. $E$ isso é algo que vai mudar na apresentação do "Retorno do Território", quando o adjetivo "utilizado" é ali incluído.

A proposta baseada no uso do território supera ainda àquela da configuração territorial, tal como apresentada na obra "Metamorfoses do 
espaço habitado" (SANTOS, 1988). A ideia da configuração territorial já anunciava algum avanço teórico em relação à associação irrestrita do território aos limites políticos do Estado. Nela está presente a sistemicidade de todas as formas, naturais ou humanizadas. Mas as ações ainda estão ausentes. É o espaço geográfico o conceito que integra as formas-conteúdo, objetos e ações (naquele momento entendidas ainda como fixos e fluxos). Razão pela qual serão diferenciados pelo autor os conceitos de paisagem (conjunto de objetos alcançados ou identificados pelo corpo), configuração territorial (a totalidade dos objetos em sistema) e espaço (o matrimônio entre configuração territorial, paisagem e sociedade).

Portanto, quando apresenta o "Retorno do Território" Milton Santos anuncia algo novo, sem, entretanto, impor uma ruptura com sua teoria da geografia até então desenvolvida. De fato, a inserção do adjetivo "utilizado" ou simplesmente "uso" ao conceito de território não pode ser considerada uma novidade na sua teoria, embora ao fazê-lo avança, integrando ao que antes era apenas uma forma ou configuração, o seu conteúdo e intencionalidade. As rugosidades do espaço, por exemplo, que é um conceito frequentemente encontrado na obra de Milton Santos (1978; 1986; 1988; 1996; entre outras) ${ }^{2}$, carregam consigo a ideia básica do uso. Evidentemente, como dado social, o uso é o que atribui significado às formas sociais e históricas. Podendo, inclusive, alterá-las, dando-lhes novos conteúdos. As rugosidades, como formas herdadas, inscrevem-se exatamente na dialética socioespacial das formas-conteúdo. Razão pela qual as ações presentes, ou seja, os usos, não podem ser entendidos sem considerar, conforme o autor, "[...] as rugosidades que definem cada pedaço do território" (Santos, 1978, p. 227).

Da mesma forma, a associação do território utilizado ao conceito de espaço banal, não é algo novo na geografia de Milton Santos. Originalmente proposto por François Perroux, o conceito de espaço banal é definido como o local de realização da vida cotidiana, o espaço de todos e, portanto, irredutível, porque reúne internamente todos os seus elementos (SANTOS, 1996). Ao espaço banal opor-se-ia a noção de redes. Em proposta anterior, não muito 
diferente, ao espaço banal, caracterizado pela concretude e proximidade, oporse-ia o espaço econômico e abstrato dos economistas (SANTOS, 1986).

Entretanto, a metáfora do "Retorno do Território" é uma forma de Milton Santos dizer que, nesse momento histórico, não é mais apenas o Estado o agente definidor da vida nos lugares e da existência do território. Em suas palavras, "[...] evoluímos da noção, tornada antiga, de Estado Territorial para a noção pós-moderna de transnacionalização do território" (SANTOS, 1994, p. 15). Razão pela qual irá associar o conceito de território utilizado ao de espaço banal, pois quer exatamente confrontá-lo à noção de redes, ou seja, ao mecanismo de transnacionalização do território. Obviamente, uma transnacionalização do território implicaria seu próprio fim. Alguns autores chegaram mesmo a propô-lo (BADIE, 1995). Outros, não querendo defender seu fim, o ressignificaram dentro do discurso de um mundo tornado reticular (CASTELLS, 2000).

No auge do discurso neoliberal, falar em redes e no fim do território (político na acepção do termo), não era muito difícil. A metáfora do retorno é, por isso, também uma crítica. Não que Milton Santos estivesse negando as redes. Aliás, sobre as redes ele mesmo reservou extensa consideração na obra "A natureza do espaço" (SANTOS, 1996). Mas à noção de redes, de um mundo verticalizado, de um acontecer hierárquico, opõe-se, conforme o autor, a noção de espaço banal, de um mundo compartido mediante regras formuladas localmente, horizontal em relação aos usos, complementar e homólogo. O espaço banal teria a primazia das formas, com a relevância das técnicas, ao passo que o espaço reticular teria a primazia das normas, com a relevância da política (SANTOS, 1994). Conclusão que assume imediatamente antes de afirmar a dialética do/no território.

Obviamente, não há separação entre as formas e as normas, ou ainda, entre um espaço banal e um reticular. Como também não há separação entre objetos e ações, formas e conteúdo, global e local, horizontalidades e verticalidades. A riqueza da teoria de Milton Santos é justamente a capacidade de integrar dialeticamente esses conceitos. E isso é feito considerando-se os 
dados da política (em sua acepção ampla) e das técnicas presentes em toda produção social do espaço humano. A dialética do/no território seria, dessa forma, constituída por "[...] um controle 'local' da parcela 'técnica' da produção e um controle remoto da parcela política da produção" (SANTOS, 1994, p. 17).

Resumidamente, na geografia de Milton Santos haveria "[..] um território de todos, frequentemente contido nos limites do trabalho de todos". A ele equivaleria o espaço banal, sinônimo de espaço geográfico. Contudo, contrapondo-se a esse território usado, compartido e próximo, há "[...] o território daquelas formas e normas ao serviço de alguns" (SANTOS, 1994, p. 18). A ele equivaleria o espaço das redes ou de todas as exterioridades determinativas do local. Portanto, há o território usado, de um lado, e o território reticular, de outro. E o que lhes dá existência e, ao mesmo tempo, os integra (ou fragmenta), é a dialética socioespacial (local e global) da técnica e da política.

\section{O USO DO TERRITÓRIO: BREVE NOTA EPISTEMOLÓGICA}

Talvez nenhum autor tenha entendido melhor a teoria do território em Milton Santos do que Ana Clara T. Ribeiro; possivelmente pela sua proximidade e identificação com o autor. De acordo com esta autora, o "retorno do território" na geografia de Milton Santos deve ser entendido como uma "[...] ponte estrategicamente posicionada entre a teoria crítica do espaço e a ação política" (RIBEIRO, 2012, p. 141. Nestes termos, porque o uso do território agrega, segunda ela, as duas "faces dessa ponte", a saber: a problemática do poder e a problemática da ação. No primeiro caso, há a centralidade da política e as relações de poder derivadas de sua produção e, no segundo caso, há a centralidade da ação, ou dos sistemas de ações, e sua materialização e realização através dos sistemas técnicos.

Isso explica o adjetivo "usado" imposto pelo autor, pois, segundo Ribeiro, é impossível dissociar as dimensões do poder e da ação dos usos propriamente ditos. Contudo, não há em Milton Santos uma visão parcial do 
poder e nem da ação. Evidencia-se, pois, uma abordagem que integra todos os elementos, todo o espaço e todas as ações; fato que novamente explica a relação que se faz entre espaço geográfico, espaço banal e território usado. Nas palavras do autor: "a compreensão do espaço geográfico como sinônimo de espaço banal obriga-nos a levar em conta todos os elementos e a perceber a inter-relação entre os fenômenos. Uma perspectiva do território usado conduz à ideia de espaço banal, o espaço de todos, todo o espaço (SANTOS, 2000, p. 104).

Portanto, não se trata de evidenciar mais diretamente um campo de forças em relação a outro e, dessa forma, categorizar o território a partir de um ponto de vista. Novamente em suas palavras: "[...] é a realidade do todo o que buscamos apreender" (SANTOS, 1996, p. 117). Mas não esse todo fugaz, inalcançável. A análise do real é ponto de partida, e a divisão do conhecimento é uma necessidade para o entendimento do território como totalidade.

De acordo com Santos (1996), o projeto de integração na análise do real a partir do conceito de território usado supõe necessariamente a divisão espacial e temporal do objeto de análise. Porém, o território (assim como o lugar) não é o fragmento, mas a totalidade em movimento. Daí a necessidade de considerar dois movimentos inseparáveis na produção do território: por um lado o movimento do todo e seus impactos seletivos ${ }^{3}$ no território e, de outro, a dinâmica do território e sua relação com o todo. O território usado existe enquanto tal graças a essa relação totalidade-particularidade, num processo constante de reprodução. Isso autoriza também a dizer que o território só pode ser entendido através do conhecimento do mundo como totalidade, agora globalizado. E o mundo como totalidade só pode ser entendido a partir do conhecimento das partes, ou seja, dos territórios como particularidades.

Corroborando essa afirmação, Santos (2000, p. 104-105) vai dizer que "[...] o território usado constitui-se como um todo complexo onde se tece uma trama de relações complementares e conflitantes. Daí o vigor do conceito, convidando a pensar processualmente as relações estabelecidas entre o lugar, a formação socioespacial e o mundo". O território usado é então entendido 
como "o espaço de todas as dimensões do acontecer, de todas as determinações da totalidade social" (SANTOS, 2000, p. 104). Visto dessa forma, ou seja, como totalidade, o território usado torna-se "[...] um campo privilegiado para a análise, na medida em que, de um lado, nos revela a estrutura global da sociedade e, de outro, a própria complexidade do seu uso" (SANTOS, 2000, p. 108).

Ou seja, o território usado não resulta da totalidade, ele mesmo é a totalidade em movimento. Efetivamente, conforme Milton Santos, o que o torna objeto de análise social é justamente a capacidade de integrar todas as ações e todas as formas simultaneamente no espaço-tempo. Razão pela qual o conceito de território usado vai inscrever-se na relação ontológica e sistêmica das ações e dos objetos espacialmente referidos e temporalmente datados. Fator que novamente explica a relação sinonímica entre território usado e espaço geográfico.

Um aspecto central na análise territorial em Milton Santos, como de toda a sua obra, é o dado informacional. A informação se constitui como a técnica das técnicas, porque as regula e as integra, afirma o autor (SANTOS, 1996). Por isso, nesse momento, ou melhor, nesse meio (técnico-científicoinformacional), os objetos não podem ser entendidos simplesmente como materialidades postas no território, mas como objetos técnicos e informacionais (são objetos sociotécnicos). Portanto, os objetos carregam em si mesmos a informação como dado de sua existência e de sua realização. Da mesma forma, as ações são cada vez mais informadas, integradas e, como dado da política, também cada vez mais normatizadas. É isso que permite a coordenação, no tempo e no espaço, dessas mesmas ações em diversas escalas. Por isso, não são ações aleatórias, desarticuladas e independentes. Há uma "lógica" que unifica e integra tudo isso e a informação é o meio técnico ou o motor completamente novo que permite a sua realização.

O mercado é essa lógica e o meio técnico-científico-informacional é a expressão geográfica que permite sua existência globalizada. A convergência tempo-espaço (convergência dos momentos) produzida por esse meio e essa 
lógica é o que determina as formas de uso do território. Nas palavras do autor, o meio técnico-científico-informacional (que é a cara geográfica da globalização) "[...] acaba por se impor a todos os territórios e a cada território como um todo" (SANTOS, 1996, p. 239).

Nessa acepção, o uso do território vai se conformando a uma racionalidade vinda de fora, tanto mais sensível quanto mais aberto para acolher esses objetos técnicos "inteligentes". De acordo com o autor, este é um dos fatores responsáveis pela diferenciação territorial, na medida em que os vetores da globalização atingem diferentemente e incompletamente todos os territórios. Entretanto, juntamente com essa lógica dita "global”, há outra, a chamada lógica "local ou territorial".

É preciso, contudo, entender que os usos territoriais passados e novos não são acolhedores passivos de uma racionalidade globalizada. Quando Milton Santos insere o conceito de "rugosidades" já antecipa esse esclarecimento, pois não se trata apenas de uma dialética socioespacial, no sentido das readequações das formas-conteúdo no espaço-tempo, mas também de um processo de contradição, cooperação e conflito entre as escalas da prática social, no sentido dos intercambiamentos, submissão e rupturas entre o global e o local. Portanto, o território usado, esse espaço banal da vida cotidiana, não deve ser analisado como uma oposição a um espaço global; fosse assim não seria possível uma "globalização dos de baixo", ou seja, "uma outra globalização" (SANTOS, 2006).

Apresenta-se, pois, a questão fundamental de saber analisar o território usado nessa perspectiva da totalidade e inseparabilidade do espaço-tempo nas diferentes escalas do acontecer social. $\mathrm{Na}$ verdade, o conceito de território usado é justamente uma forma de enfrentar essa questão, um modo produzir, segundo o autor, uma geografia totalmente empiricizável. E para integrar as escalas na discussão sistêmica das ações-objetos é proposta a noção de "redes sociotécnicas" (SANTOS, 1996).

As redes sociotécnicas envolvem toda materialidade e a vida que as anima. Na teoria do território elas são fundamentais porque como dado social e 
técnico elas se realizam pelas relações de trabalho. E o uso do território manifesta, em síntese, as diferentes divisões territoriais do trabalho. A complexidade do entendimento do uso do território ocorre porque, do ponto de vista geográfico e histórico, as divisões territoriais do trabalho se justapõem e superpõem, simultaneamente. A proposição da repartição atual do "trabalho vivo" sobre um acúmulo histórico de um "trabalho morto" é exemplo significativo disso na obra do autor.

Portanto, é na perspectiva da divisão territorial do trabalho que a dialética do/no território deve ser entendida. Não sem razão, pois é assim que se produzem no território as diferentes densidades e funcionalidades, assim como as incompatibilidades de velocidades, a exemplo de expressões como "espaços de rapidez e de lentidão"; "espaços luminosos e opacos”; "espaços da fluidez e da viscosidade"; "espaços que mandam e obedecem". Por isso, o estudo do território brasileiro em obra conjunta com Maria Laura Silveira (SANTOS E SILVEIRA, 2001) talvez seja a que melhor expressa a implementação prática do conceito de território usado, pois investiga exatamente essas incompatibilidades de velocidades, as divisões territoriais do trabalho e os usos efetivamente.

Essas considerações, ainda que abreviadas, do conceito de território na geografia de Milton Santos são elucidativas para uma proposição e aplicação condizente com a teoria. Com a devida cautela, obviamente, uma vez que as possibilidades teóricas do conceito descredenciam qualquer definição disciplinarmente rígida, linear e unificada.

\section{TERRITÓRIO USADO E SAÚDE: INSERÇÕES, ADAPTAÇÕES E INCORREÇÕES}

O conceito de território em Milton Santos foi amplamente incorporado nas propostas de territorialização dos serviços de saúde do SUS. A descentralização dos serviços, associada à progressiva municipalização da gestão, colocou a necessidade de uma política sistematizada de planejamento 
territorial. Efetivamente, conforme Faria (2011), os princípios constitutivos do SUS (universalidade, equidade e integralidade) dependem fundamentalmente de uma organização territorial do sistema, pois a oferta (a existência dos serviços nos lugares) e o acesso (o uso equitativo e integrado) são processos relacionados ao território. $E$ isso é uma novidade, pois nos sistemas fragmentados e hierárquicos anteriores era insípida a relação entre os serviços, a população e o território. Em outras palavras, o planejamento territorial era algo ainda secundário porque não havia, pelo menos de modo sistematizado e para todo o país, a identificação entre os serviços e uma população adscrita territorialmente.

Isso muda com a municipalização do sistema de atenção e o fortalecimento da atenção básica à saúde do SUS a partir da década de 1990 (PAIM, 1992). É quando são propostas as primeiras oficinas de territorialização utilizadas para criar sistemas locais de saúde (SILOS), popularmente conhecidos no Brasil como "distritos sanitários" (VILLAROSA, 1993). A adoção do modelo (e estratégia) Saúde da Família ${ }^{4}$ na organização dos serviços de atenção básica ainda na década de 1990 irá aprofundar o debate territorializador da saúde no município. Dessa forma, à medida que os distritos sanitários vão caindo no ostracismo como modo de organização territorial da saúde nos municípios, as áreas de atuação das Equipes Saúde da Família (ESF) vão se tornando a forma privilegiada de definir a porta de entrada do SUS (FARIA, 2013a).

Sob o discurso territorializador o conceito de território usado generalizouse no Brasil. A natureza empírica do conceito talvez tenha contribuído. Efetivamente, o uso envolve a prática social, ou seja, uma existência objetiva e histórica, material e simbólica. O que torna sua compreensão relativamente acessível mesmo aos profissionais não acostumados com a discussão territorial.

O problema, entretanto, é que, na acepção teórica proposta por Milton Santos, o conceito de território usado jamais poderia se aplicar a uma política de territorialização da saúde. Nem na teoria e muito mesmo na prática. Isso foi 


\section{TERRITÓRIO E SAÚDE NA GEOGRAFIA DE MILTON SANTOS: TEORIA E MÉTODO PARA O PLANEJAMENTO TERRITORIAL DO SISTEMA ÚNICO DE SAÚDE NO BRASIL}

rapidamente destacado por Souza (2004), que, talvez pela sua obviedade ou porque não considerasse necessário, nem mesmo quis aprofundar a questão. Resumidamente, em suas palavras:

Fala-se muito hoje em territorialização da saúde. Isto é um enorme equívoco. Vimos anteriormente que o território usado é algo que se impõe a tudo e a todos. Logo, falar em territorialização de uma coisa é uma tautologia, pois todas as coisas necessariamente estão "territorializadas". Nada pode ser adjetivado com território. Ele é inerente a existência das coisas. É, portanto, errado falar em "territorialidade da saúde", pois ela só pode significar um uso do território, este é inerente a ela. A discussão, portanto, é outra: aquela da distribuição sócioespacial ou sócio-territorial dos serviços de interesse social, inclusive a saúde (SOUZA, 2004, p. 70).

Elemento de distinção mais importante e claramente expresso pela autora: a proposta da territorialização da saúde altera o princípio básico da totalidade de todos os objetos e ações sistemicamente expressos através uso (social e histórico) do território. Essa questão foi também apresentada por Faria e Bortolozzi (2012) no estudo das diferentes "tipologias de territorialização da saúde no Brasil”. A terminologia, dizem, já encaminha os sentidos do termo: efetivamente, a territorialização é um processo de produção/criação de territórios. Entretanto, o processo não se define a si mesmo senão em relação ao que o desencadeia. Neste caso, portanto, as territorialidades. Essa distinção foi muito bem delineada por Sack (1986), para quem as territorialidades são a estratégia, ao passo que a territorialização é o seu processo resultante.

Evidentemente, isso não poderia se aplicar à teoria do território em Milton Santos, pois não se trata de considerar o processo, nem as estratégias, mas o uso social e histórico que envolve ambos e revela uma realidade territorial e política do presente. A própria questão da escala do acontecer social não poderia se adequar ao debate da territorialização, pois, na acepção miltoniana, as escalas se realizam pelas redes sociotécnicas e como relações territoriais sistemicamente integradas (e fragmentadas). Portanto, não são os 
processos entre as escalas o que está em questão, mas o território produzido e usado pela dinâmica conflituosa e/ou complementar entre uma realidade, ao mesmo tempo, local e global.

É importante ter em conta as inúmeras propostas de territorialização da saúde no Brasil. Para efeitos, recomendam-se os trabalhos de Faria e Bortolozzi (2012); Faria (2012; 2013b). Obviamente, nem todas as propostas são baseadas na teoria do território em Milton Santos. Em fins da década de 1980 e início de 1990, por exemplo, quando a territorialização esteve associada à distritalização, não havia uma teoria do território a ela associada. Importante que se diga que as primeiras oficinas de territorialização foram majoritariamente desenvolvidas por profissionais da saúde. O geógrafo era uma figura secundária, quando não completamente ausente. Por isso, os principais manuais utilizados para organizar os distritos sanitários nos municípios, como Mendes (1993); Villarosa (1992); Almeida, Castro e Lisboa (1998), entre outros, são baseados na literatura da Saúde Coletiva, da Administração ou Sociologia. Razão que explica, por exemplo, a forte influência teórica do Planejamento Estratégico Situacional (PES) de Carlos Matus (1993) na definição de metodologias de territorialização da saúde no Brasil. É exemplo de maior relevância o trabalho desenvolvido por Unglert (1993; 1995), possivelmente uma das primeiras a sistematizar oficinas de territorialização da saúde no Brasil. Outras propostas de planejamento territorial do SUS incorporarão a teoria baseada no PES (MENDES, 1993; TEIXEIRA, PAIM e VILASBOAS, 1998; VILLAROSA, 1992; entre outros).

Todavia, embora ainda tímida em fins da década de 1980 e início de 1990, é possível notar alguma influência teórica de Milton Santos nas propostas de territorialização da saúde no Brasil. A mais importante e que fundamenta os principais manuais de distritalização dos serviços de saúde do SUS é a proposta teórica baseada no chamado "território-processo". Essa expressão, originalmente apresentada por Mendes (1993), foi uma das melhores tentativas de superação da visão reducionista baseada no "territórioproduto" (físico-topográfico; político-administrativo). Abreviadamente, o autor 
propõe pensar o território para além de suas geometrias (com intuito claro de superar uma visão burocrática e inflexível do planejamento territorial), mas como um processo social em permanente construção e transformação. Malgrado a boa intenção, não há, por parte do autor, nenhuma fundamentação teórica baseada no conceito de território; nem mesmo em relação aos processos de territorialização-desterritorialização-reterritorialização (TDR). Evidentemente, ao fundamentar sua proposta no "processo", Mendes (1993) quer privilegiar a natureza transitória (e dinâmica) do território. Entretanto, o autor não faz nenhuma referência às teorias baseadas nos processos de TDR, mas, sim, à obra "Economia Espacial” de Milton Santos (1979b).

O conceito de território usado será efetivamente inserido nas propostas de territorialização da saúde nesse início do século. É quando o conceito se amplia na própria geografia miltoniana. São exemplos os trabalhos de Monken (2003, 2008); Monken e Barcellos (2005, 2007); Gondin (2011); Gondin et al (2008); entre outros. Em geral, mesmo na sua acepção mais ampla, como propõe Monken (2008), a territorialização é definida como uma técnica ou tecnologia de planejamento territorial ou ainda como um conjunto de metodologias utilizadas para desencadear o processo de apropriação do território pelos serviços de saúde. Os modos de apropriação podem variar (há diferentes metodologias para a implementação de oficinas de territorialização), mas o fundamento teórico desencadeador é o mesmo. E este fundamento (o processo), com seu modus operandi, é incondizente com conceito de território usado.

As propostas de territorialização, em geral, buscam uma conciliação teórica com a geografia de Milton Santos. Um autor que enveredou explicitamente nessa empresa foi o próprio Monken (2003; 2008). Desenvolver uma tecnologia educacional para a aprendizagem da territorialização, eis a proposta por ele apresentada. Contudo, aprender a fazer a territorialização equivale a aprender a criar territórios. Evidentemente, o território é sempre socialmente criado, mas não se "aprende a criá-lo", senão, isto sim, pode-se aprender a compreendê-lo e, dessa forma, planejá-lo. Por isso, sem embargo, 
uma tecnologia de aprendizagem baseada na territorialização é um modo de criar limites territoriais para os serviços. E tal como é toda criação, uma nova realidade se projeta e se impõe. Objetivamente, o que se impõe na territorialização da saúde é um limite novo, nomeadamente definido como o limite de atuação dos serviços de saúde. Mas o território já existe como totalidade. Não se cria outro território ou outro limite. A não ser que a concepção esteja fundamentada naquela da multiterritorialidade (HAESBAERT, 2004) ou simplesmente na sua elaboração político-administrativa. Mas não há, obviamente, multiterritorialidade em Milton Santos e a perspectiva administrativa é superada na sua proposta do "Retorno". O uso pode ser pluralizado, mas como um dado social e histórico ele reflete o movimento do todo social. Do contrário, estaria fadado o projeto de totalidade tão caro na geografia de Milton Santos.

Portanto, em termos de planejamento, não se trata de criar territórios para os serviços, mas, sim, de adaptá-los aos territórios (FARIA, 2013b). O território usado permite perscrutá-lo, reconhecê-lo, como o fez o próprio Milton Santos ao definir os "quatro brasis" (SANTOS e SILVEIRA, 2001). As ações de planejamento e de desenvolvimento são feitas sobre essa estrutura material e simbólica do presente, sobre esse conteúdo corpóreo e imaterial presente sistemicamente nos objetos e ações. Sobre isso, não há mais o que aprofundar.

Depois de mais de duas décadas de descentralização do SUS no Brasil, as orientações para o planejamento territorial foram também incorporando o discurso territorializador. Hoje já são encontradas orientações específicas em instrumentos oficiais do Ministério da Saúde ou das Secretarias Estaduais e Municipais de saúde. O Plano Nacional de Atenção Básica à Saúde (PNAB), por exemplo, recomenda que a definição dos territórios de atuação das Equipes Saúde da Família seja feita através da territorialização dos serviços (BRASIL, 2012). Importante que se diga que a territorialização é uma normativa, um princípio de organização desses serviços. Se essa prática é positiva ou não será necessário considerar seus resultados práticos (FARIA, 
2013b). Tal como se apresenta, a definimos como uma prática política de criação de limites, condicionada por determinantes igualmente políticos e burocráticos como, por exemplo, a adscrição da clientela (cada unidade de saúde deve atender um público-alvo numericamente definido).

Um dos instrumentos mais importantes a definir o arranjo assistencial e territorial dos serviços públicos de saúde no Brasil, a saber, o "Pacto pela Vida, em Defesa do SUS e a Gestão" (BRASIL, 2006a), nos oferece uma dimensão do que se tornou a territorialização da saúde no país. Conforme a Portaria № 399, entre suas muitas funções, o Pacto "reforça a territorialização da saúde como base para organização dos sistemas, estruturando as regiões sanitárias e instituindo colegiados de gestão regional” (BRASIL, 2006b, inciso III).

Não é surpresa que os instrumentos normativos pós Pacto irão sistematicamente insistir no princípio da territorialização dos serviços de saúde do SUS. E não raro, será a geografia miltoniana a referência básica para sua constituição. São exemplos: a Política Nacional de Humanização do SUS (BRASIL, 2010); Política Nacional de Atenção Básica (BRASIL, 2012); as orientações para o planejamento dadas em Cadernos de Atenção Básica (BRASIL, 2009; 2014); as diretrizes para a modelagem das redes de atenção à saúde do SUS (BRASIL, 2008; 2010), entre outras. Embora tais instrumentos, porque são normativas, não informem as referências bibliográficas, é de se supor que estejam fundamentadas nas propostas e nas reflexões sobre a territorialização em desenvolvimento na academia. Não sem razão, pois é exatamente nesse período, designadamente pós-Pacto, que o debate sobre a territorialização se generalizou no país. São contributos nesse sentido os trabalhos de Monken (2008); Monken e Barcellos (2007); Gondin (2011); Gondin et al (2008); Barcellos e Pereira (2006); Gadelha et al (2011); Pessoa et al (2013), entre muitos outros. De tal forma que o conceito teve que ser incluído no Dicionário de Educação Profissional em Saúde (GONDIN e MONKEN, 2008), dada sua importância como uma tecnologia de planejamento dos serviços. 


\section{TERRITÓRIO E SAÚDE NA GEOGRAFIA DE MILTON SANTOS: TEORIA E MÉTODO PARA O PLANEJAMENTO TERRITORIAL DO SISTEMA ÚNICO DE SAÚDE NO BRASIL}

Entretanto, ainda são poucos os estudos que se dedicam a perscrutar os sentidos e, principalmente, os resultados práticos desse modelo de planejamento baseado na territorialização da saúde. Há mais consenso do que dissenso, não há dúvida. Por outro lado, ainda são poucos trabalhos alternativos para o planejamento territorial, ou seja, capazes de estabelecer uma proposta diferente. E, finalmente, mesmo as abordagens mais fundamentadas teoricamente, carecem de aprofundamento de método, sobretudo quando estão relacionados com a prática. A implantação do Plano Diretor da Atenção Primária à Saúde em Minas Gerais (ESPMG, 2008) é exemplo significativo disso. Há, explicitamente, uma filiação miltoniana, mas não há nenhum aprofundamento teórico que a justifique.

Por outro lado, não há dúvida, a teoria do uso do território, tal como nos apresenta Milton Santos, é, de fato, muito eficaz para as ações de planejamento territorial, não apenas do SUS. Não se pode negar que a generalização do conceito esteja também ligada à sua potencialidade. Aplicado adequadamente, conforme Faria (2013b), o território usado permite um trabalho de reconhecimento, identificação e adaptação (nessa ordem). Obviamente, se o território se define pelo uso, o modo mais adequado de entendê-lo é perscrutando se uso. Isso deve anteceder qualquer ação prática de alocação dos serviços e de definição do público-alvo. As ações democráticas e participativas, assim como a intersetorialidade das ações, algo tão caro no arranjo territorial do SUS, são processos transversais (no sentido de que antecedem e acompanham as ações) e também fazem parte do planejamento baseado no uso do território. Podem, inclusive, ser facilitadas porque os arranjos da atenção serão baseados na adaptação dos serviços ao território. Não há dúvida, essa é uma mudança em relação ao encaminhamento conceitual em torno da territorialização: não se trata de criar territórios, mas de adaptar os serviços aos territórios (reflexão aprofundada a esse respeito foi feita por Faria (2012; 2013b)). Em resumo, no que concerne a produção de uma tecnologia de planejamento territorial, a perspectiva baseada no uso do 
território deve encaminhar uma prática condizente com a teoria que a fundamenta. E a esse respeito, esperamos ter dado alguma contribuição.

\section{CONSIDERAÇÕES FINAIS}

A geografia miltoniana é certamente uma das mais influentes no planejamento territorial dos serviços de saúde do SUS no Brasil. Isso é positivo, dada a grandeza teórica e de método oferecida por esse autor. No que concerne ao conceito de território, sua proposta baseada no uso permitiu integrar sua teoria, historicamente fundamentada na discussão sistêmica dos objetos e ações (fixos e fluxos; formas-conteúdo) definidoras e produtoras de espaço. Não há desarranjo ou corte na sua geografia, embora seja perfeitamente reconhecida sua intenção de avançar a compreensão do território para além da dimensão política administrativa ou da configuração territorial. Por isso, é compreensível que o conceito de território esteja mais densamente presente em sua "última geografia" (MORAES, 2013).

Nomeadamente em relação à discussão conceitual do território usado (ou uso do território) há dois textos centrais e indispensáveis para o seu entendimento, um dos quais exercerá maior influência na saúde, dada sua vocação do retorno (SANTOS, 1994 e 2000). Mas é no Manifesto que o conceito é mais aprofundadamente discutido, talvez pela forte integração à sua obra prima, e certamente mais densa, sobre a "Natureza do Espaço" (SANTOS, 1996). Ali o conceito de território usado aparece explicitamente, como que aprofundando o seu retorno. E, finalmente, era necessário dar um contorno empírico à discussão conceitual, assim como o havia feito outras obras. Isso é magistralmente feito na sua obra conjunta com Maria L. Silveira (SANTOS e SILVEIRA, 2001). Ali o conceito de território usado é, então, efetivamente aplicado. Razão que explica a forte influência dessa obra nas abordagens do planejamento territorial do SUS. Efetivamente, a dimensão empírica intencionalmente dada pelos autores irá contribuir para isso (o 
território usado, dizem, permite a produção de um conhecimento geográfico totalmente empiricizável).

O uso, esse adjetivo acrescentado ao conceito de território, é o que permite a Milton Santos considerá-lo como um equivalente ao espaço banal ou ainda sinonimicamente ao espaço geográfico. O território usado é o espaço de todos, todo o espaço, lugar do acontecer social (SANTOS, 1994). Assim o define, porque quer deixar clara a noção de totalidade implícita ao conceito. Efetivamente, o uso expressa exatamente essa totalidade: não há separação entre um espaço reticular e outro zonal ou ainda entre uma realidade local e outra global. Portanto, a técnica (e as redes sociotécnicas) e a política (fundamento da sua teoria crítica do espaço), como dados da ação e do poder, não são dimensões separadas da existência social e histórica ou das escalas do acontecer. É fato que o território usado expressa a contiguidade (aquilo que é complementar e homólogo), as passo que as redes expressam as descontinuidades (aquilo que é vertical e hierárquico). Mas não há, definitivamente, um cotidiano compartido, de um lado, e um mundo reticular, de outro. Senão que se tratam de realidades integradas (embora, não sem tensões).

Nomeadamente em relação ao planejamento territorial dos serviços de saúde do SUS, acredita-se, essa noção de totalidade é perdida. Isso fica claro na aplicação do conceito de território usado nas propostas de territorialização da saúde no país. E sabemos que não há, peremptoriamente, uma discussão da territorialização em Milton Santos. Pela razão simples de que de tal empresa fere o princípio da totalidade pretendida pelo autor. Ou ainda, de modo mais categórico, conforme Souza (2004), não há uma territorialidade da saúde (princípio para a existência de uma territorialização), mas o território inerente da todas as coisas.

Portanto, a criação de uma tecnologia de planejamento baseada na territorialização da saúde é incoerente com a teoria do território na geografia de Milton Santos. Não significa que sua proposta teórica não deva ser utilizada para a produção de uma metodologia de planejamento. Isso foi feito, por 


\section{TERRITÓRIO E SAÚDE NA GEOGRAFIA DE MILTON SANTOS: TEORIA E MÉTODO PARA O PLANEJAMENTO TERRITORIAL DO SISTEMA ÚNICO DE SAÚDE NO BRASIL}

exemplo, por Faria (2012), num trabalho teórico e prático de reconhecimento dos perfis territoriais da saúde a partir do uso do território. Não significa também que as propostas de territorialização produzidas com enorme esforço por inúmeros autores não tenha, cada uma à sua maneira, enorme relevância no planejamento dos serviços de saúde do SUS. Mas há que se cuidar para que a leitura equivocada do conceito encaminhe uma prática de planejamento igualmente equivocada. É fundamental perguntar se a apropriação do território pelos serviços de saúde (ou a "criação" de limites territoriais) é uma prática adequada aos princípios de universalidade, equidade e integralidade do SUS. É ainda fundamental uma avaliação abrangente dos resultados dessa prática, em curso desde a década de 1990. Por fim, e não menos importante, é necessário repensar teórica e metodologicamente o planejamento territorial do SUS à luz e nos termos propostos por Milton Santos.

\section{NOTAS}

(1) Efetivamente, a leitura do território na obra de Milton Santos deve ser feita, conforme Moraes (2014), considerando uma sucessão e acúmulo de influências teóricas e filosóficas: os primeiros trabalhos sob influência da geografia francesa (1950-1960); a convergência teórica para o existencialismo, principalmente através das leituras de Jean Paul Sartre; a aproximação com o marxismo estruturalista, de influência althusseriana, quando os temas da cidade e do urbano ou ainda da organização espacial do mundo subdesenvolvido são predominantes (19670-1990); a incorporação da teoria dos sistemas e ainda a aproximação com os teóricos da Escola de Frankfurt, nomeadamente Adorno, Horkheimer e Marcuse (1980); a inserção das perspectivas da filosofia fenomenológica na sua teoria do espaço (1990).

(2) Mencione-se que algumas dessas obras como "O trabalho do Geógrafo no Terceiro Mundo" e "Por uma Geografia Nova" foram publicadas originalmente em francês alguns anos antes da tradução para o português. Portanto, é necessário considerar que essas obras expressam teóricas que vêm sendo desenvolvidas em fins da década de 1960 e início de 1970.

(3) Este é o princípio da diferenciação dos lugares, uma vez que "a transformação do todo, que é uma integral, em suas partes - que são as suas diferenciais, dá-se, também, por uma distribuição ordenada, no espaço, dos impactos do todo" (SANTOS, 1996, p. 125). 
(4) O "Programa Saúde da Família" (PSF) foi criado em 1994 a partir das experiências bem sucedidas que vinham sendo feitas com o Programa "Agentes Comunitários da Saúde" (PACS). Ainda na década de 1990 e mais efetivamente no início do século o programa foi incorporando uma dimensão estratégica, deixando as limitações financeiras e temporais próprias de um programa (ROSA e LABATE, 2005).

\section{AGRADECIMENTOS}

À Coordenadoria de Aperfeiçoamento de Pessoal de Nível Superior (CAPES), pelo financiamento.

\section{REFERÊNCIAS BIBLIOGRÁFICAS}

ALMEIDA, E. S.; CASTRO, C. G. J.; LISBOA, C. A. Distritos Sanitários: concepção e organização. São Paulo: FSP/USP, 1998. 47p.

BADIE, Bertrand. O fim dos territórios. Lisboa: Instituto Piaget, 1995. 304p BARRETO, M. L. Esquistossomose Mansônica: Distribuição da Doença e Organização Social do Espaço. 1982. 102f. Dissertação (Mestrado em Medicina Preventiva) - Departamento de Medicina Preventiva, Universidade Federal da Bahia, Salvador, 1982.

BRASIL. Ministério da Saúde. Cadernos de Atenção Básica. Diretrizes do Núcleo de Apoio à Saúde da Família. Brasília: Ministério da Saúde, 2009. 152p. BRASIL. Ministério da Saúde. Cadernos de Atenção Básica. Diretrizes do Núcleo de Apoio à Saúde da Família. Brasília: Ministério da Saúde, 2014. 116p. BRASIL. Ministério da Saúde. Diretrizes operacionais para os pactos pela vida, em defesa do SUS e de gestão. Brasília: Ministério da Saúde, 2006a. $76 p$.

BRASIL. Ministério da Saúde. Portaria № 4.279: Estabelece as diretrizes para a organização da Rede de Atenção à Saúde no âmbito do Sistema Único de Saúde (SUS). Diário Oficial da União, Brasília, 31 de dezembro de 2010.

BRASIL. Ministério da Saúde. Redes regionalizadas de atenção à saúde: contexto, premissas, diretrizes gerais, agenda tripartite para discussão e 
proposta de metodologia para apoio à implementação. Brasília: Ministério da Saúde, 2008. 55p.

BRASIL. Ministério da Saúde. Política Nacional de Atenção Básica. Brasília: Ministério da Saúde, 2012. 110p.

BRASIL. Ministério da Saúde. Política Nacional de Humanização do SUS. Brasília: Ministério da Saúde, 2010. 242p.

BRASIL. Portaria № 399, de 22 de fevereiro de 2006. Divulga o Pacto pela Saúde - Consolidação do SUS e aprova as Diretrizes Operacionais do Referido Pacto. Brasília: Ministério da Saúde, 2006b.

CASTELLS, M. A sociedade em rede. 4. ed. São Paulo, São Paulo: Paz e Terra, 2000. 617 p.

CZERESNIA, D.; RIBEIRO, A. M. O conceito de espaço em epidemiologia: uma interpretação histórica e epistemológica. Cadernos de Saúde Pública, Rio de Janeiro, v. 16, n. 3, p. 595-613, 2000.

ESPMG - Escola de Saúde Publica de Minas Gerais. Implantação do Plano Diretor da Atenção Primária à Saúde. Oficina 1: Redes de Atenção à Saúde. Belo Horizonte: ESPMG, 2008. 56p.

FARIA, R. A Territorialização da atenção primária à saúde no Sistema Único de Saúde e a construção de uma perspectiva de adequação dos serviços aos perfis do território. Hygeia, Uberlândia, v. 6, n. 16, 2013b, p. 131-147.

FARIA, R. A territorialização como política e como tecnologia de gestão dos serviços de atenção primária à saúde no âmbito do Sistema Único de Saúde: análise de uma prática geográfica da saúde. In: BORTOLOZZI, A. (org.). Cidades reivindicadas: territórios da luta, das utopias e do prazer. São Paulo: Olho d'água, 2011, p. 29-47.

FARIA, R. A territorialização da atenção primária à saúde no Sistema Único de Saúde: perspectivas de adequação aos perfis do território urbano de Pouso Alegre-MG. 2012. 320f. Tese (Doutorado em Geografia) - Instituto de Geociências, Universidade Estadual de Campinas, Campinas, 2012. 
FARIA, R. Os desiguais limites da porta de entrada do Sistema Único de Saúde (SUS) em Pouso Alegre, Minas Gerais, Brasil. Ra'eGa: O Espaço Geográfico em Análise, Curitiba, v. 29, p. 135-156, $2013 a$.

FARIA, R. M. de; BORTOLOZZI, A. A territorialização como proposta para a organização da Atenção Básica no âmbito do SUS: análise de uma prática geográfica da saúde. Geografia, Rio Claro, v. 37, n. 3, p. 431-444, 2012.

FARIA, R. M. de; BORTOLOZZI, A. Espaço, território e saúde: contribuições de Milton Santos para o tema da Geografia da Saúde no Brasil. Ra'eGa: O Espaço Geográfico em Análise, Curitiba, n. 17, p. 31-41, 2009.

GADELHA, Carlos A. G. et al. Saúde e territorialização na perspectiva do desenvolvimento. Ciência e Saúde Coletiva, Rio de Janeiro, v. 16, n. 6, p. 3003-3016, 2011.

GEORGE, P. et al. A geografia ativa. São Paulo, SP: Difusão Europeia do Livro: USP, 1966. 359p.

GONDIM. G. M. M. et al. O território da saúde: a organização do sistema de saúde e a territorialização. In: BARCELLOS, C. et al (org.). Território, ambiente e saúde. Rio de Janeiro: Editora Fiocruz, 2008, p. 237-255.

GONDIM. G. M. M. Territórios da Atenção Básica: múltiplos, singulares ou inexistentes? 2011. 256f. Tese (Doutorado em Saúde Pública) - Escola Nacional de Saúde Pública Sérgio Arouca, Fiocruz, Rio de Janeiro, 2011.

GONDIN, G. M. M; MONKEN, M. Territorialização em saúde. In: PEREIRA, I. B.; LIMA, J. C. F. (org.). Dicionário de educação profissional em saúde. 2. ed. Rio de Janeiro: EPSVJ, 2008, p. 392-399.

HAESBAERT, R. O mito da desterritorialização: do "fim dos territórios" à multiterritorialidade. 2. ed. Rio de Janeiro: Bertrand Brasil, 2004. 395p.

LACAZ, C. S. et al (Org.). Introdução à Geografia Médica do Brasil. São Paulo: Editora da Universidade de São Paulo; 1972. 568p.

MATUS, C. Política, planejamento e governo. Tomos I e II. Brasília: Instituto de Pesquisa Econômica Aplicada (IPEA), 1993. 143p. 
MENDES, E. V. et al (org.). Distrito Sanitário: o processo social de mudança das práticas sanitárias do Sistema Único de Saúde. São Paulo, Hucitec, 1993. 310p.

MONKEN, M. Contexto, território e processo de territorialização de informações. Desenvolvendo estratégias pedagógicas para a educação profissional em vigilância em saúde. In: BARCELLOS, C. (org.). A geografia e o contexto dos problemas de saúde. Rio de Janeiro: Abrasco, 2008, p. 141163.

MONKEN, M. Desenvolvimento de tecnologia educacional a partir de uma abordagem geográfica para a aprendizagem da territorialização em vigilância à saúde. 2003. 170f. Tese (Doutorado em Saúde Pública) - Escola Nacional de Saúde Pública, FIOCRUZ, Rio de Janeiro, 2003.

MONKEN, M.; BARCELLOS, C. O Território na Promoção e Vigilância em Saúde. CORBO, A. M. A.; FONSECA, A. F. O território e o processo saúdedoença. Rio de Janeiro: EPSJV/Fiocruz, 2007, p. 177-224.

MONKEN, M.; BARCELLOS, C. Vigilância à saúde e território utilizado: possibilidades teóricas e metodológicas. Rio de Janeiro, Cadernos de Saúde Pública, Rio de Janeiro, v. 21, n. 3, p. 898-906, 2005.

MORAES, A. C. R. Território na Geografia de Milton Santos. São Paulo: Annablume, 2013, $130 \mathrm{p}$.

PAIM, J. S. A reforma sanitária e a municipalização. Rio de Janeiro, Saúde e Sociedade, São Paulo, v. 1, n. 2, p. 29-47, 1992.

PEREIRA; M. P. B.; BARCELlOS, C. O território no Programa Saúde da Família. Hygeia, Uberlândia, v.2, n. 2, p. 47-55, 2006.

PESSOA, S. B. Ensaios Médico-Sociais. 2. ed. São Paulo: Editora Hucitec, 1978. 380p.

PESSOA, Vanira Matos. Sentidos e métodos de territorialização na atenção primária à saúde. Ciência e Saúde Coletiva, Rio de Janeiro, v. 18, n. 8, p. 2253-2262, 2013.

RIBEIRO, A. C. T. Por uma sociologia do presente: ação, técnica e espaço. 3. ed. Letra Capital, 2012. 142p. 
ROSA, W. A. G.; LABATE, R. C. Programa Saúde da Família: a construção de um novo modelo de assistência. Rev. Latino-Americana de Enfermagem, Ribeirão Preto, v. 13, n. 6, p. 1027-34, 2005.

SACK, R. Human territoriality: Its theory and history. Cambridge: Cambridge University Press, 1986. 256p.

SANTOS, M. A Natureza do Espaço: técnica, razão e emoção. São Paulo: Hucitec, 1996. 308p.

SANTOS, M. Espaço e método. São Paulo: Nobel, 1985. 88p.

SANTOS, M. Metamorfose do espaço habitado. São Paulo: Hucitec, 1988. $124 \mathrm{p}$.

SANTOS, M. O papel ativo da geografia: um manifesto. Revista Território, Rio de Janeiro, n. 9, p. 103-109, 2000.

SANTOS, M. O Retorno do Território. In: SANTOS, M. et al. (org.). Território: globalização e fragmentação. São Paulo, SP: Hucitec, 1994, p. 15-20.

SANTOS, M. Por Uma Geografia Nova. São Paulo: Hucitec, 1978. 236p.

SANTOS, M. Por uma outra globalização: do pensamento único à consciência universal 13. ed. Rio de Janeiro: Record, 2006. 174p.

SANTOS, M. Saúde e ambiente no processo de desenvolvimento. Ciência e Saúde Coletiva, Rio de Janeiro, n. 1, v. 8, p. 309-314, 2003.

SANTOS, M.; SILVEIRA, M. O Brasil: território e sociedade no início do século XXI. Rio de Janeiro: Record, 2001. 471p.

SANTOS, M. Economia espacial: críticas e alternativas. São Paulo, SP: Hucitec, 1979b. 167p.

SANTOS, M. O espaço dividido: os dois circuitos da economia urbana dos países subdesenvolvidos. Rio de Janeiro: Francisco Alves, 1979a. 345p.

SANTOS, M. O espaço do cidadão. São Paulo, SP: Nobel, 1987. 142p.

SANTOS, M. O trabalho do geógrafo no terceiro mundo. 2. ed. São Paulo: Hucitec, 1986. 113p.

SILVA, L. J. Organização do Espaço e Doença. In: CARVALHEIRO, J. R (org.). Textos de Apoio: Epidemiologia I. 2. ed. Rio de Janeiro, 1985, p. 159-185. 
SOUZA, M. A. A. Uso do território e saúde: refletindo sobre "municípios saudáveis". In: SPERANDIO, A. M. G. O processo de construção de municípios potencialmente saudáveis. Campinas: IPES Editorial, 2004, p. 57-77.

TEIXEIRA, C. F., PAIM, J. S.; VILASBOAS, A. L. SUS: modelos assistenciais e vigilância da saúde. Brasília, Informe Epidemiológico SUS, Brasília, v. 7, n.2, p. 7-28, 1998.

UNGLERT, C. V. de S. Territorialização em saúde: a conquista do espaço local enquanto prática do planejamento ascendente. 1995. 221f. Tese (Livre docência) - Universidade de São Paulo, Faculdade de Saúde Pública, São Paulo, 1995.

UNGLERT, C. V. de S. Territorialização em Sistemas de Saúde. In: MENDES, E. V. (org). Distritos Sanitários: processo social de mudança nas práticas sanitárias para o Sistema Único de Saúde. São Paulo: Hucitec: Abrasco, 1993, p 221-235.

VILLAROSA, F. N. D. A estimativa rápida e a divisão do território no distrito sanitário. Brasília: OPS: OMS, 1993. 54p 